SAJJAD SAMIEE, Ph.D.

(Corresponding author)

E-mail: s.samiee@tugraz.at

Graz University of Technology

Institute of Automotive Engineering

Inffeldgasse 11, Graz 8010, Austria

SHAHRAM AZADI, Ph.D.

E-mail: Azadi@kntu.ac.ir

REZA KAZEMI, Ph.D.

E-mail: kazemi@kntu.ac.ir

K. N. Toosi University of Technology

Faculty of Mechanical Engineering

Tehran 19991-43344, Iran

ARNO EICHBERGER, Ph.D.

E-mail: arno.eichberger@tugraz.at

Graz University of Technology

Institute of Automotive Engineering

Inffeldgasse 11, Graz 8010, Austria
Intelligent Transport Systems (ITS)

Original Scientific Paper

Submitted: Apr. 4, 2015

Accepted: Dec. 1, 2015

\title{
TOWARDS A DECISION-MAKING ALGORITHM FOR AUTOMATIC LANE CHANGE MANOEUVRE CONSIDERING TRAFFIC DYNAMICS
}

\begin{abstract}
This paper proposes a novel algorithm for decision-making on autonomous lane change manoeuvre in vehicles. The proposed approach defines a number of constraints, based on the vehicle's dynamics and environmental conditions, which must be satisfied for a safe and comfortable lane change manoeuvre. Inclusion of the lateral position of other vehicles on the road and the tyre-road friction are the main advantages of the proposed algorithm. To develop the lane change manoeuvre decision-making algorithm, first, the equations for the lateral movement of the vehicle in terms of manoeuvre time are produced. Then, the critical manoeuvring time is calculated on the basis of the constraints. Finally, the decision is made on the feasibility of carrying out the manoeuvre by comparing the critical times. Numerous simulations, taking into account the tyre-road friction and vehicles' inertia and velocity, are conducted to compute the critical times and a model named TUG-LCA is presented based on the corresponding results.
\end{abstract}

\section{KEY WORDS}

autonomous driving; lane change manoeuvre; decision making; Drive Assistance System;

\section{INTRODUCTION}

Lane change manoeuvres are an important part of microscopic traffic simulations, and significantly affect the results produced by these simulations [1]. Lane changes contribute to a significant percentage of the collisions due to wrong estimation of distances between the vehicles by the drivers [2]. Wang et al. report that $20 \%$ of the highway collisions occur due to the inappropriate lane changes [3].

Studies on lane change have been conducted for around three decades, e.g. [4]. In [5] a group of 16 drivers was gathered to investigate the characteristics of lane change. The characteristics examined included lane change duration and required distance as well as the initial position of the vehicle. This study showed that the driver's age and the direction of lane change do not influence the aforementioned characteristics.

Another research based on the use of a driving simulator for steering wheel data recording during lane change showed that the type of the front vehicle does not affect the manoeuvre duration and maximum angle of the steering wheel, while the velocity of the front vehicle influences the aforementioned characteristics [6]. In [7], a model was developed for vehicle lane change based on the cellular automaton (CA) which mainly focused on some of the vehicle's constraints such as maximum acceleration and deceleration. The rules used in [7] were later used in another study for traffic simulation in double- and triple-lane highways in [8] and it was demonstrated that the developed model allows realistic simulations.

A Multi-input Multi-output adaptive neuro-fuzzy system was used in [9] to model the driver behaviour during the lane change based on realistic data. The developed model exhibited satisfactory performance even in the presence of operation delay. In the research conducted by Song et al. [10] for the design of emergency lane change path (automated lane change 
due to driver inability to control the vehicle), a model was proposed based on the artificial potential approach and the elastic band theory, which can be used in different circumstances such as driving on straight and curved paths as well as lane change manoeuvres. In this study, yaw rate and lateral vehicle acceleration were used to evaluate the generated path. In another study, an algorithm was proposed which is able to identify the boundaries of the path, store the obtained information and design the desirable driving path using a vectorial approach [11]. In [12] the driving task was interpreted as a model predictive control which is able to control and stabilize the double-lane change manoeuvre using fuzzy logic in accordance with the ISO standard. The aforementioned approach was also employed in another study [13] to control vehicle velocity in addition to the lane change manoeuvring. The experiments conducted on a one-way two-lane road demonstrated suitable longitudinal and lateral control action of the vehicle consistent with the traffic condition of the road.

In research carried out by Zhang et al. [14], the process of path design was adapted to the driving condition. In this approach, first the optimal steering angle is computed by forming a trade-off between vehicle performance and passenger comfort and then a lane change path is suggested based on the calculated angle and in accordance to the dynamic constraints of the vehicle. Finally, if no collision occurs between the vehicles on the suggested path, it would be se- lected as the final path. In [15], some models were proposed for passenger cars and heavy vehicles using accurate camera information and analysis of experimental recorded data. By inclusion of car-following behaviour and taking dynamic constraints into account, a new model was developed which allowed for velocity change during vehicle manoeuvring [16]. This model was simple and more consistent with the real lane change behaviour of the drivers. During a research on parameters affecting the vehicle lane change process, it was revealed that the shape and duration of a manoeuvre do not depend on the leading vehicle and are only influenced by the starting point of the manoeuvre [17]. Moreover, in this study a simple mathematical model was developed based on the optimization of the consumed fuel during the manoeuvre.

In all aforementioned studies, decision-making unit considers only the initial condition of traffic vehicles and assumes there will be no changes in their behaviour during the lane change manoeuvre. Hence, in case of any changes in traffic movement, the system will not be able to correct its primary decision. The innovation of the proposed algorithm is the integration of process dynamics which enables the system to modify the manoeuvre if any environmental change appears in the middle of the lane change. The inclusion of the effect of lateral displacement of all vehicles, taking tyre-road friction into account, respecting vehicle dynamics, and providing real-time performance are the other advantages of the proposed system.

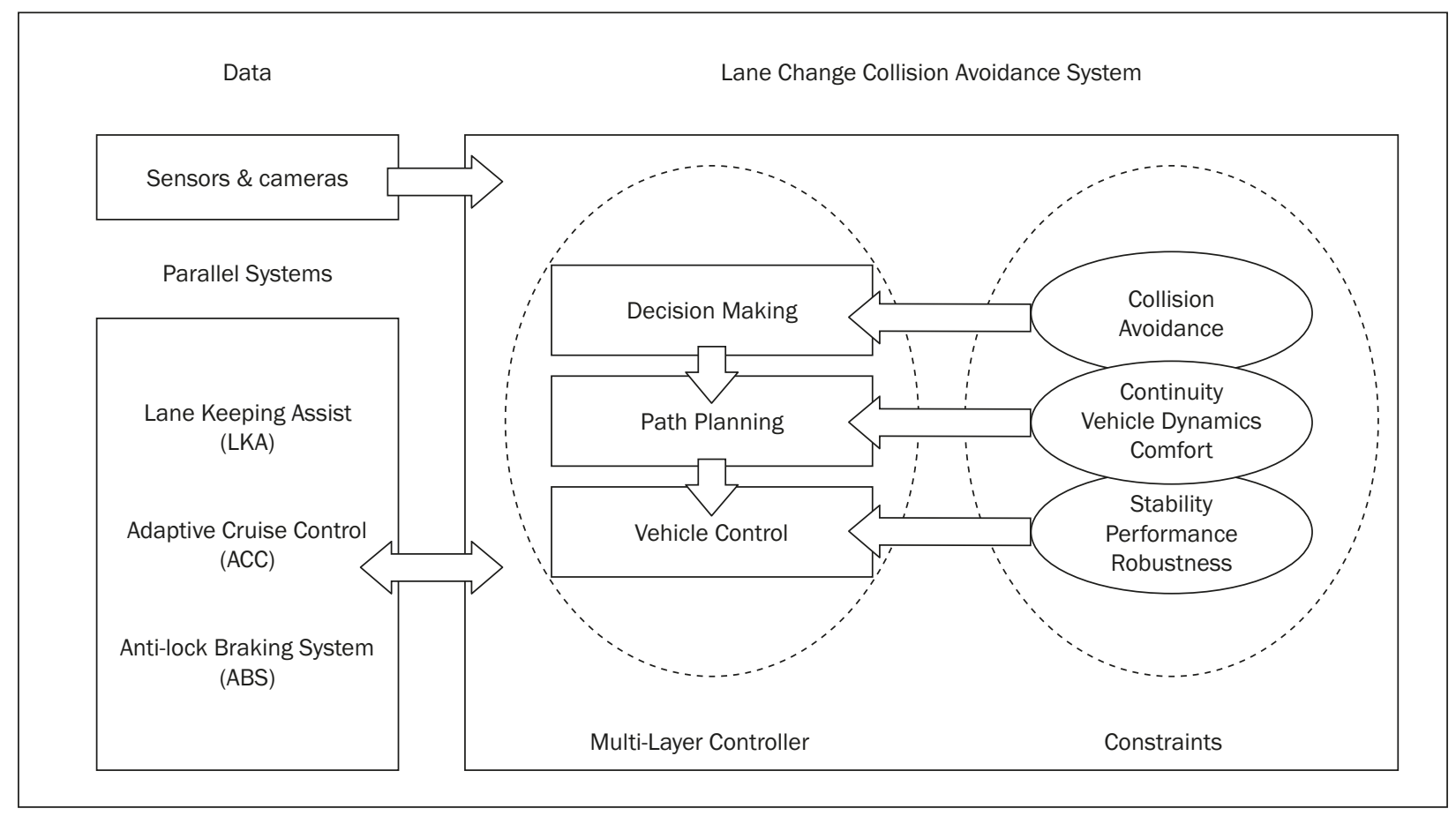

Figure 1 - Schematic structure of multi-layer lane change controller 


\section{AUTOMATIC LANE CHANGE SYSTEM}

In general, a lane change control system consists of three layers. Figure 1 shows an illustration of different layers of this system and the one-way top-down format of signal flow between these layers. This figure also presents the system interface to other driver assistance systems.

The first layer embraces the decision-making system which investigates the possibility of a lane change by using sensor data and comparing the ego (lane changer) vehicle's position to other vehicles. In the second layer, the vehicle's trajectory is generated. The generated trajectory must fulfil the dynamic constraints of the vehicle and can be optimized based on different measures such as safety, passenger comfort or fuel consumption. Finally, the third layer carries out the steering of the vehicle on the designed trajectory.

In this study, the conventional format of one-way top-down signal flow between the layers of automatic lane change algorithm (see Figure 1) has been modified. In the proposed algorithm, as demonstrated in Figure 2, the Decision Making (DM) unit gathers all required information from the sensors and decides if the lane change is possible. Then, it transfers the corresponding data to Path Planning (PP) unit where the initial path is designed. If the traffic behaviour and road condition do not change during the manoeuvre, the Vehicle Control (VC) unit guides the vehicle to follow the initial designed path for a safe lane change. If any changes appear in the middle of the manoeuvre so that the initial path is not safe anymore, then the DM is able to correct its primary decision to avoid any collision. It delivers all the updated data to Path

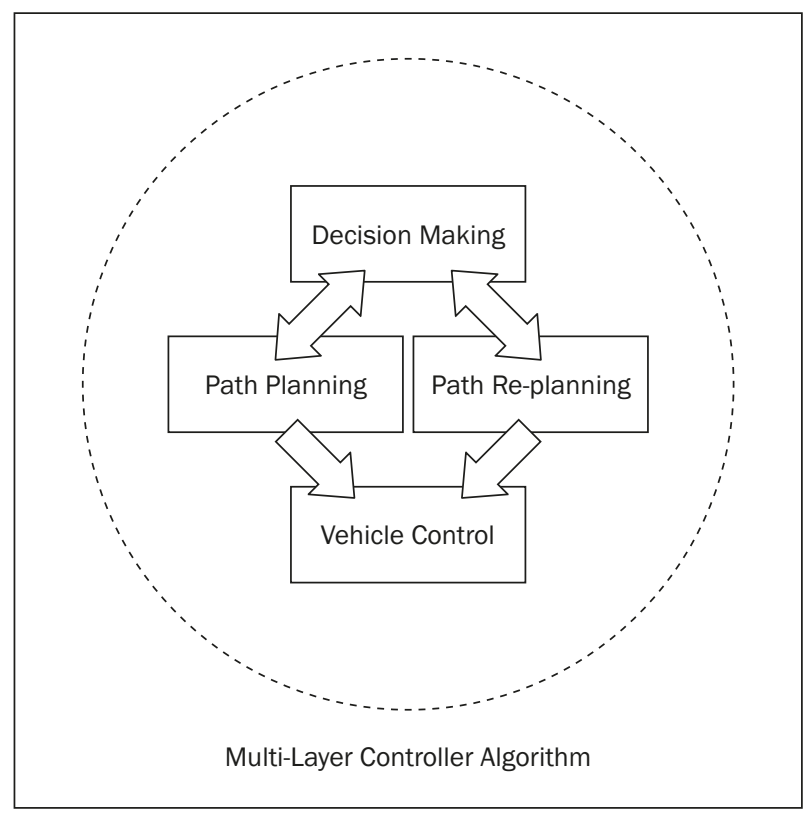

Figure 2 - The configuration of the developed automatic lane change algorithm
Re-planning (PR) unit for redesigning a safe path. This task can be repeated several times during the lane change manoeuvre based on environment traffic behaviour. The design of PP, PR, and VC units are not discussed here and this study mainly focuses on the development of the DM Unit.

It is clear that like the conventional lane change system, the proposed algorithm has to satisfy constraints such as vehicle dynamics, stability, continuity, and robustness. In addition, it should be able to operate in cooperation with Advanced Driver Assistance Systems (ADAS) such as LKA and ACC.

\section{PROBLEM DEFINITION AND PROPOSED APPROACH}

In this study it is assumed that the vehicle is being driven on a straight, level highway without any intersections. Due to some reasons, such as driver's drowsiness or heart attack, the vehicle is intended to be steered toward the right side of the road to avoid collision with other vehicles. This manoeuvre needs to be done in presence of other vehicles in a dynamic traffic environment.

During this manoeuvre, the longitudinal velocity of the vehicle is assumed to be constant. These assumptions are usually valid during lane change in normal condition. Hence, the trajectory equation can be derived by expressing the lateral displacement of the vehicle in terms of time,

$y(t)=a t^{5}+b t^{4}+c t^{3}+d t^{2}+e t+f$

where $y$ is lateral displacement of the vehicle, $t$ represents time, and a to $f$ are factors of the polynomial which needs to be defined for the definition of the lane change path. The displacement and lateral velocity of the vehicle at the beginning and end of the manoeuvre are zero. In addition, based on the assumption in [20], and considering the vehicle constant longitudinal velocity during the lane change, lateral acceleration at the beginning and end of the manoeuvre can be set to zero. The mathematical representations of the aforementioned assumptions are

$$
\begin{aligned}
& \left.y\right|_{t=0}=0,\left.\quad \dot{y}\right|_{t=0}=0,\left.\quad \ddot{y}\right|_{t=0}=0 \\
& \left.y\right|_{t=t_{m}}=-h,\left.\quad \dot{y}\right|_{t=t_{m}}=0,\left.\quad \ddot{y}\right|_{t=t_{m}}=0
\end{aligned}
$$

In this research, $x$ axis of the ground based coordinate directed toward the highway and vehicles movement direction. Besides, $y$ axis is selected such that $z$ axis is upward and perpendicular to the road surface. The selected coordinate is illustrated in Figure 3-a. In equation (2), the maximum value of $h$ equals the maximum lateral displacement of the vehicle at the end of the manoeuvre. The negative sign indicates lane change to the right side of the road. Moreover, $t_{m}$ represents the manoeuvre time. By applying conditions of 
(2) to equation (1) the trajectory equation is obtained, which is the basis for this research

$y(t)=\left(\frac{-6 h}{t_{m}^{5}}\right) t^{5}+\left(\frac{15 h}{t_{m}^{4}}\right) t^{4}+\left(\frac{-10 h}{t_{m}^{3}}\right) t^{3}$,

As mentioned earlier, the decision on the lane change must be made in the presence of other vehicles and in a dynamic environment. It is assumed that, in the worst-case scenario there are three other surrounding vehicles during the manoeuvre, as shown in Figure 3. Vehicle $E$ represents the ego (lane changer) vehicle, vehicle $A$ represents the leading vehicle at the same lane, and vehicles $B$ and $D$ are leading and rear vehicles on the target lane, respectively. Possible rear vehicle on the same lane is considered not to affect the manoeuvre and therefore neglected. Moreover, the dashed-line vehicle in Figure 3 indicates vehicle $E$ during the manoeuvre. Next it will be shown that if the four conditions below are satisfied, the lane change manoeuvre will be possible:

1) During the manoeuvre, the lateral distance between the right front corner of vehicle $E$ and right rear corner of vehicle $B$ must be at least $C_{1}$ (Figure 3-a);

2) After the manoeuvre and movement of vehicle $E$ to the target lane, its distance from vehicle $B$ must be $\mathrm{C}_{2}$ (Figure 3-b);

3) During the manoeuvre, the lateral distance from the right rear corner of vehicle $E$ to the left front corner of vehicle $D$ must be at least $C_{3}$. Moreover, after the manoeuvre, the longitudinal distance between these vehicles must be at least $C_{4}$ (Figure 3-c);

4) The generated lateral acceleration of $E$ during the manoeuvre must be achievable, considering the prevailing friction potential between the road and the tyre.

The proposed decision-making algorithm investigates the possibility of designing a trajectory, considering all the abovementioned constraints. If a trajectory is feasible, the algorithm allows the manoeuvre within the suggested time; otherwise, the ego vehicle is kept on the current lane until appropriate manoeuvre conditions are available.

The decision-making algorithm focuses on time as the main decision-making parameter. First, the lane change duration for the most critical trajectory in terms of each constraint is derived.

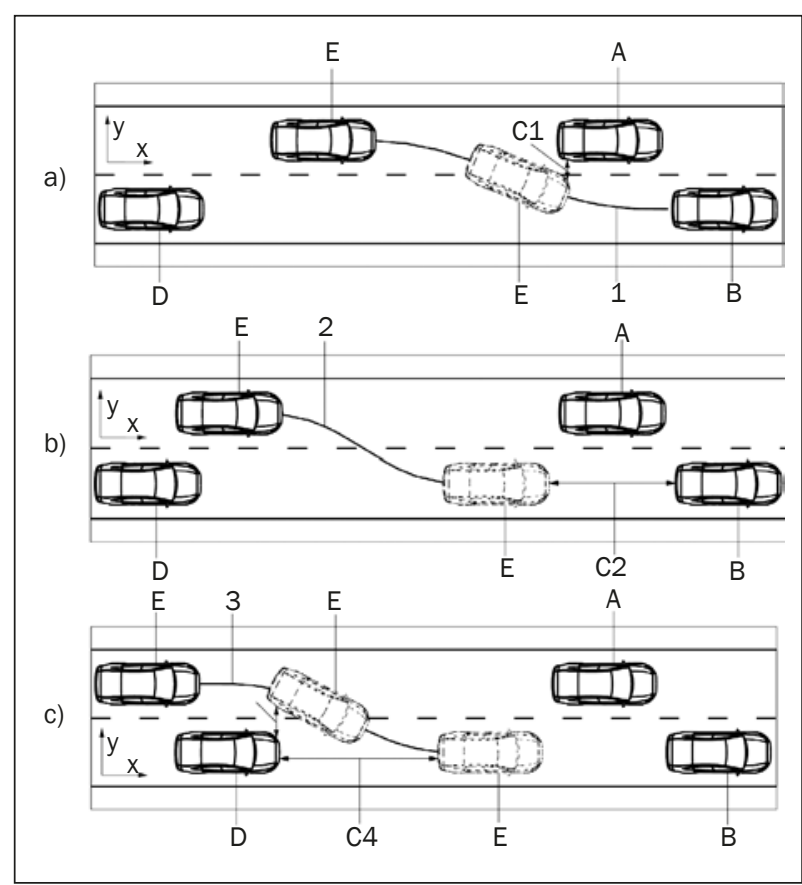

Figure 3 - Definition of constraints in lane change manoeuvre

Then, the decision on lane change possibility is made by comparing the computed lane change durations. Further, the methodology of calculating critical trajectories based on each of the aforementioned constraints will be described.

\subsection{Case 1: A vehicle in front on the same lane}

Considering Figure 3 -a, during the lane change the left front corner of vehicle $E$ (point $P$ ) will touch the right rear corner of vehicle $A$ (point $M$ ) if $C_{1}$ is zero. A magnified illustration of this situation is shown in Figure 4.

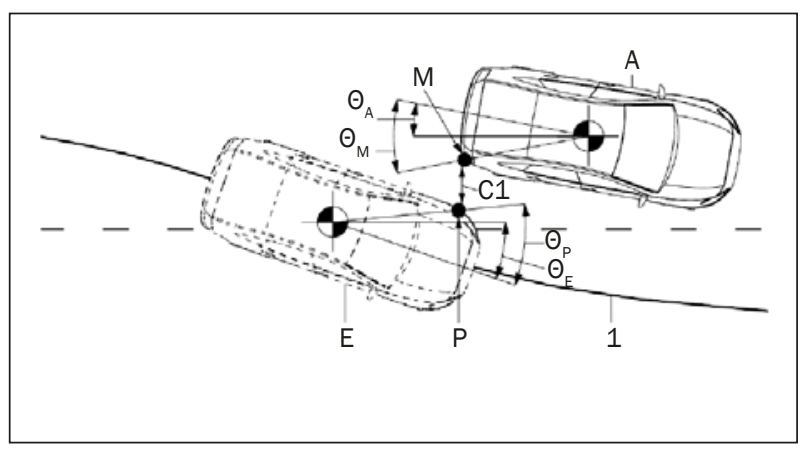

Figure 4 - Illustration of lateral constraint between ego vehicle and vehicle in front on the same lane

Considering the safe distance of $C_{1}$ between the vehicles when their longitudinal coordinates coincide, one will obtain: 


$$
\begin{aligned}
y_{A}(t)-y_{E}(t)= & C_{1}+\overline{O_{A} M} \sin \left(\theta_{M}-\theta_{A}(t)\right)+ \\
& +\overline{O_{E} P} \sin \left(\theta_{P}-\theta_{E}(t)\right)
\end{aligned}
$$

where $y_{A}(t)$ and $y_{E}(t)$ indicate the lateral position of the centre of gravity of vehicles $A$ and $E$, respectively, while $\overline{O_{E} P}$ is the length of the imaginary line connecting vehicle E's centre of gravity to point $P$ and can be computed using,

$$
\left.\overline{O_{E} P}=\sqrt{\left(\frac{1}{2}\right.} w_{E}\right)^{2}+\left(I_{E f}\right)^{2}
$$

where $I_{E f}$ indicates the longitudinal distance from vehicle $E$ 's centre of gravity to the vehicle's front and $w_{E}$ is the width of vehicle $E$. On the other hand, in equation (4), $\theta_{P}$ is the angle between $\overline{O_{E} P}$ and longitudinal axis of the vehicle, hence:

$$
\theta_{p}=\tan ^{-1}\left(\frac{W_{E}}{2 I_{E f}}\right)
$$

Similarly, parameter $\overline{\mathrm{O}_{A} M}$ in equation (4) indicates the length of the imaginary line between vehicle $A$ 's center of gravity and point $M$ and $\theta_{M}$ is the angle between $O_{A} M$ and longitudinal axis of the vehicle. Therefore,

$$
\begin{aligned}
& \overline{O_{A} M}=\sqrt{\left(\frac{1}{2} w_{A}\right)^{2}+\left(I_{A r}\right)^{2}} \\
& \theta_{M}=\tan ^{-1}\left(\frac{W_{A}}{2 I_{A r}}\right)
\end{aligned}
$$

where $I_{A r}$ indicates the longitudinal distance from vehicle A's centre of gravity to the vehicle's rear and W_A is the width of vehicle A. In addition, in equation (4), parameter $\theta \_A(t)$ is the angle between the vehicle's longitudinal axis and the horizon while $\theta_{-} E(\mathrm{t})$ represents the angle between the longitudinal axis of vehicle $E$ and the horizon at any moment. These parameters can be computed by,

$$
\tan \left(\theta_{E}(t)\right)=\frac{\partial y_{E}(t)}{\partial x_{E}(t)}=\frac{v_{y E(t)}}{v_{X E}}
$$

where $v_{x E}$ and $v_{y E}$ are the longitudinal and lateral velocity of the ego vehicle in the global coordinate system. Based on equation (8), the following is obtained,

$$
\begin{aligned}
& \sin \left(\theta_{E}(t)\right)=\frac{v_{Y E}(t)}{\sqrt{\left(V_{X E}\right)^{2}+\left(V_{Y E}(t)\right)^{2}}} \\
& \cos \left(\theta_{E}(t)\right)=\frac{V_{X E}}{\sqrt{\left(V_{X E}\right)^{2}+\left(V_{Y E}(t)\right)^{2}}}
\end{aligned}
$$

The condition for longitudinal coincidence of points $P$ and $M$ can be stated by

$$
x_{A}-\overline{O_{A} M} \cos \left(\theta_{M}-\theta_{A}(t)\right)=x_{E}+\overline{O_{E} P} \cos \left(\theta_{P}-\theta_{E}(t)\right)
$$

By substituting (5)-(8) and (10-11) into (4) and using the numerical technique presented in [21], one can solve (4) and obtain the manoeuvre duration $t_{m}$ such that constraint $C_{1}$ is satisfied. This time is labelled as $t_{1}$. Obviously, this constraint designates all trajectories in which the lateral distance between $M$ and $P$ is greater than $C_{1}$, as a candidate for a safe trajectory. The value of $C_{1}$ itself can be a function of environmental conditions and the desirable safety factor.

\subsection{Case 2: Another vehicle in front and on the target lane}

Various studies have addressed the issue of the minimum safe longitudinal distance between two vehicles and several formulations have been developed for this distance, e.g. [22, 23]. In this study, the method proposed by Juala et al. [24] is employed. In this conservative method, it is assumed that the velocity of the front vehicle suddenly becomes zero in case of collision with an obstacle. In this circumstance, the safety distance is obtained as,

$C_{2}=s_{0}+v_{x E} t_{d}+\frac{v_{x E}^{2}}{2 a_{E b}}$

In (12), $s_{0}$ is the safe stopping distance, while $a_{E b}$ is the maximum acceleration of vehicle $E$. In addition, $t_{d}$ is the reaction time of the driver which depends on various factors such as physical and mental condition of the driver as well as road conditions and usually varies between 0.67 and 1.11 [25]. In case when automatic braking systems are used, such as emergency braking system (EBS), $t_{d}$ is reduced. Moreover, the maximum deceleration is determined based on different conditions such as the actual value of tyre-road friction. Finally, by substituting all required parameters in (12), $\mathrm{C}_{2}$ and hence the manoeuvre time, labelled $t_{2}$, can be obtained. Hence, at the specified time instant, the longitudinal and lateral positions of two vehicle are governed by (13) and (14),

$$
\begin{aligned}
& x_{B}-x_{E}=S_{0}+v_{X E} t_{d}+\frac{v_{X E}^{2}}{2 a_{E b}}+I_{E f}+I_{B r} \\
& y_{B}=y_{E}
\end{aligned}
$$

where $x_{B}$ and $y_{B}$ indicate the longitudinal and lateral positions of the centre of gravity of vehicle $B$, respectively, and $I_{B r}$ indicates the longitudinal distance from vehicle B's centre of gravity to the vehicle's rear. Obviously, this constraint designates all trajectories in which the longitudinal distance between centres of gravity of vehicles $E$ and $B$ at the end of the manoeuvre is greater than the value obtained in (13), as a candidate for a safe trajectory.

\subsection{Case 3: A vehicle behind and on the target lane}

This case is a combination of the first two cases. To obtain the lane change duration, firstly the appropriate manoeuvre time is computed based on the safe lateral distance using (15). Then, the suitable manoeuvre time is obtained using the safe longitudinal distance at the end of the manoeuvre using (16). As the behaviour of vehicle $D$ is controlled by the automatic system, the possibility of sudden velocity change is almost negligible and hence a two-second law [26] is used instead of the conservative method in case two. Finally, the 
higher value among the two obtained values is introduced as $t_{3}$. The aforementioned equations are

$$
\begin{aligned}
y_{E}(t)-y_{D}(t)= & C_{3}+\overline{O_{D} N} \sin \left(\theta_{N}-\theta_{D}(t)+\right. \\
& +\overline{O_{E} Q} \sin \left(\theta_{E}(t)\right) \\
x_{E}-X_{D}=2 v_{x D} & +I_{E r}+I_{D f}
\end{aligned}
$$

In equations (15-16), $x_{D}(t)$ and $y_{D}(t)$ represent the longitudinal and lateral position of vehicle D's centre of gravity. Moreover, $v_{x D}$ and $I_{D f}$ indicate the longitudinal velocity of vehicle $D$ and the longitudinal distance from vehicle D's centre of gravity to the vehicle's rear, respectively. $\overline{O_{E} Q}$ is the length of the imaginary line between vehicle E's centre of gravity and right rear corner of the vehicle, i.e. point $Q$, and is calculated by,

$$
\overline{O_{E} Q}=\sqrt{\left(\frac{1}{2} W_{E}\right)^{2}+\left(I_{E r}\right)^{2}}
$$

where $I_{E r}$ is the longitudinal distance between vehicle $E$ 's centre of gravity and its rear. Moreover, $\theta_{Q}$ in (15) indicates the angle between $\mathrm{O}_{\mathrm{E}} \mathrm{Q}$ and longitudinal axis of the vehicle. Now, one can state

$$
\theta_{Q}=\tan ^{-1}\left(\frac{W_{E}}{2 I_{E r}}\right)
$$

Similarly, $\overline{O_{D} N}$ in (15) shows the length of the imaginary line from the gravity centre of vehicle $D$ and its left front corner (Point $N$ ). Moreover, $\theta_{N}$ indicates the angle between this line and longitudinal axis of the vehicle and read

$$
\begin{aligned}
& \overline{O_{D} N}=\sqrt{\left(\frac{1}{2} W_{D}\right) 2+\left(I_{D f}\right)^{2}} \\
& \theta_{N}=\tan ^{-1}\left(\frac{W_{D}}{2 I_{D f}}\right)
\end{aligned}
$$

In equations (19-20), $w_{D}$ indicates vehicle D's width. A larger illustration of the vehicles condition in this case is shown in Figure 5.

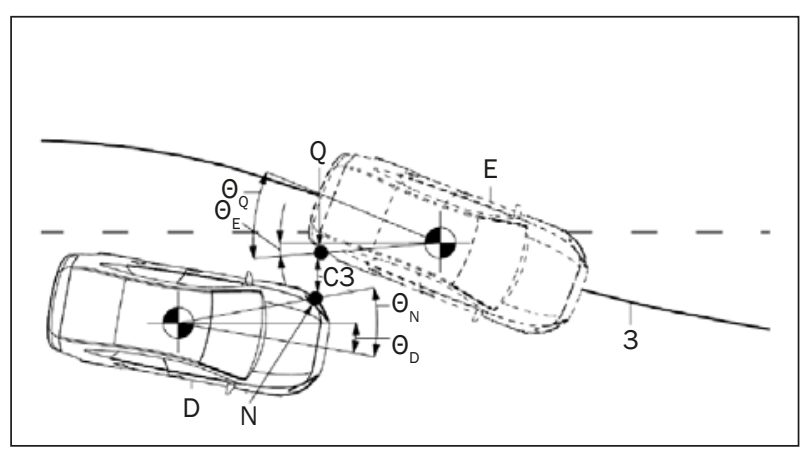

Figure 5 - Illustration of lateral constraint between ego vehicle and vehicle behind on the target lane

\subsection{Case 4: No vehicle on the lane}

In this case, there is no vehicle around the ego vehicle. Hence, it is sufficient to calculate a certain time duration $t_{m}$ for the lane change manoeuvre. The only necessary constraint is the prevailing tyre-road friction potential.

To date, various studies have been carried out based on the real driving data or driving simulation data to calculate lane change manoeuvre duration preferred by human drivers [27-31]. Table 1 presents a summary of the obtained results.

Based on Table 1, the average time of $4.3 \mathrm{~s}$ has been taken for lane change manoeuvre. This time has been obtained on highways when there is no pressure on the driver, and hence, is suitable for this study. Setting $t_{m}=4.3$ (s) and lateral displacement to the width of the highway trajectory, i.e. $\mathrm{h}=3.75(\mathrm{~m})$, the trajectory equation for this case, generally presented in (3), can be obtained as,

$$
y(t)=-0.015 t^{5}+0.165 t^{4}-0.472 t^{3}
$$

The lateral displacement, velocity and acceleration of the trajectory in terms of time are shown in Figure 6. As seen in this figure, the maximum lateral acceleration on this trajectory is about $1.2 \mathrm{~m} / \mathrm{s}^{2}$, which maintains passenger comfort.

Table 1 - A summary of different studies on lane change time duration

\begin{tabular}{||c|c|c|c|c|c||}
\hline \multirow{2}{*}{ Source } & \multirow{2}{*}{ Year } & \multicolumn{4}{|c|}{ Lane change duration (s) } \\
\cline { 3 - 6 } & & Min & Max & Avg. & S. D. \\
\hline \hline Salvucci & 2002 & - & - & 5.14 & 0.86 \\
\hline Lee & 2006 & - & - & 6.28 & 2 \\
\hline Toeldo & 2007 & 1 & 13.3 & 4.6 & 2.3 \\
\hline Thiemann & 2008 & - & - & 4.01 & 2.31 \\
\hline Gurupackiam & 2012 & 2.6 & 6 & 4.19 & 0.81 \\
\hline Cao & 2013 & 1 & 6.8 & 2.54 & 1.29 \\
\hline
\end{tabular}




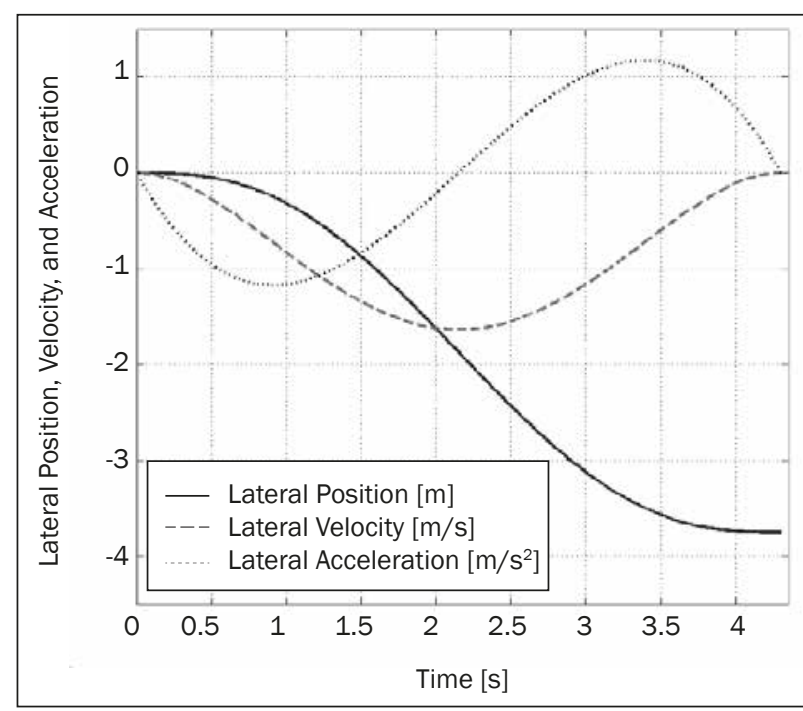

Figure 6 - Lateral displacement, velocity and acceleration during a lane change based on case four

\subsection{Case 5: The most aggressive lane change}

The designed trajectory for the vehicle must be feasible with respect to vehicle dynamics. In other words, in addition to continuity and differentiability of the trajectory, the dynamic constraints of the vehicle must be satisfied. In particular, in case of the lane change, it must be ensured that the generated lateral acceleration during the manoeuvre is attainable, considering maximum tyre-road friction coefficient, and that vehicle stability can be maintained.

To ensure this, the duration of the most severe lane-change manoeuvre must be computed and then the trajectory designed which allows a manoeuvre time duration greater than the duration of the most severe lane-change manoeuvre. In this case, the dynamic equation of the vehicle at the lateral axis can be stated by,

$m\left(a_{y}+r v_{x}-p v_{z}\right)=F_{y}$

where $p$ is the roll rate, $r$ indicates the yaw rate, $a_{y}$ represents the lateral acceleration of the vehicle, $v_{x}$ and $v_{z}$ are longitudinal and perpendicular velocity of the vehicle, $m$ is vehicle's weight and $F_{y}$ is the lateral force applied to the vehicle and obtained by,

$F_{y}=\sum_{i=1}^{4}\left(F_{x i} \sin \left(\delta_{i}\right)+F_{y i} \cos \left(\delta_{i}\right)\right)$

where $F_{x i}, F_{y i}$ and $\delta_{i}$ are longitudinal force, lateral force and steering angle of $i$-th wheel, respectively. If the vehicle travels through the path which was obtained from equation (3), lateral acceleration can be calculated using,

$\ddot{y}=\left(\frac{-120 h}{t_{m}^{5}}\right) t^{3}+\left(\frac{180 h}{t_{m}^{4}}\right) t^{2}+\left(\frac{-60 h}{t_{m}^{3}}\right) t$
By substituting $h=3.75(\mathrm{~m})$ into $(24)$, the maximum lateral acceleration at the following time instants can be obtained,

$t=\frac{t_{m}(1 \pm \sqrt{1 / 3})}{2}$

After substituting (25) into (24), the maximum lateral acceleration can be computed as follows,

$\left|\left(a_{y}\right)_{\max }\right|=\frac{21.65}{t_{m}^{2}}$

Obviously, the lateral acceleration increase is proportional to the square of manoeuvre time duration and to achieve higher acceleration, manoeuvre time must be decreased. By substituting (22) into (26), $\left(t_{m}\right)_{\min }$ is obtained.

$\left(t_{m}\right)_{\min }=\sqrt{\frac{21.65}{\max \left(\frac{1}{m} F_{y}-r v_{x}+p v_{z}\right)}}$

Hence, the influence of the vehicle dynamics and prevailing road conditions on the minimum lane change time is taken into account. The lateral force produced beneath each tyre, $F_{y i}$, depends on the lateral slip angle and can be computed using (28) based on the Fialla model [32],

$\alpha_{i}=\delta_{i}-\tan ^{-1}\left(\frac{\left(v_{y}+r \cdot I_{x i}\right)}{\left(v_{x}-r \cdot I_{y i}\right)}\right)$

where $\alpha_{i}$ and $\delta_{i}$ are lateral slip angle and steering angle associated with wheel $i$. Besides, $I_{x i}$ and $I_{y i}$ are the longitudinal and lateral distance between each tyre and the vehicle's centre of gravity, while $v_{y}$ represents lateral velocity of the vehicle. On the other hand, when the respective tyre is facing longitudinal and lateral slip, the longitudinal and lateral forces are interrelated based on the elliptic friction model [33] which reads,

$\left(\frac{F_{x i}}{\mu_{x i} F_{z i}}\right)^{2}+\left(\frac{F_{y i}}{\mu_{y i} F_{z i}}\right)^{2}=1$

where $F_{z i}, \mu_{x i}$ and $\mu_{y i}$ are perpendicular force, longitudinal friction coefficient and lateral friction coefficient of tyre $i$, respectively. According to (23) and (27)-(29), it is inferred that the shortest lane change duration, $\left(t_{m}\right)_{\min }$ depends on different parameters such as vehicle acceleration, tyre performance, road conditions and some characteristics of the vehicle, e.g. weight and the distance from front and rear axles to the gravity centre.

Next, the minimum lane change time is derived as a function of three variables, including the longitudinal velocity, weight and friction. These factors, apart from the level of influence, take time-varying values. In a specific vehicle, the weight may change depending on the number of passengers or loading volume. Similarly, the maximum tyre-road friction coefficient depends on the road condition as well as the tyre characteristics. Finally, lane change manoeuvre may be carried out at different velocities. The vehicle's weight and velocity can be easily measured instantaneously and there are different methods to estimate maximum tyre-road 
friction coefficient in real time, as stated in [34]. In this study, other parameters such as the distance between front and rear axles of the vehicle are assumed to be constant. The dynamic vehicle simulation tool, IPG CarMaker, is used in this paper for analysis.

\subsubsection{Applied Dynamic Simulation Software}

IPG CarMaker is a platform to simulate vehicle dynamics and control units [35]. This tool provides a comprehensive setting for implementing driving scenarios and can be used for offline and real-time simulations for hardware-in-the-loop systems [36]. The models in IPG CarMaker are parametric, hence allowing generation of a variety of models. The development of comprehensive vehicle systems such as power train, steering, braking and tyre system can be realized [37]. Moreover, C-language codes can be added to the program and communication with MATLAB/ SIMUINK adds to the enhanced flexibility of the tool [38]. The results obtained from the pre-set models in this tool have been used and verified in various studies $[39,40]$. A general view of the IPG CarMaker GUI is illustrated in Figure 7.

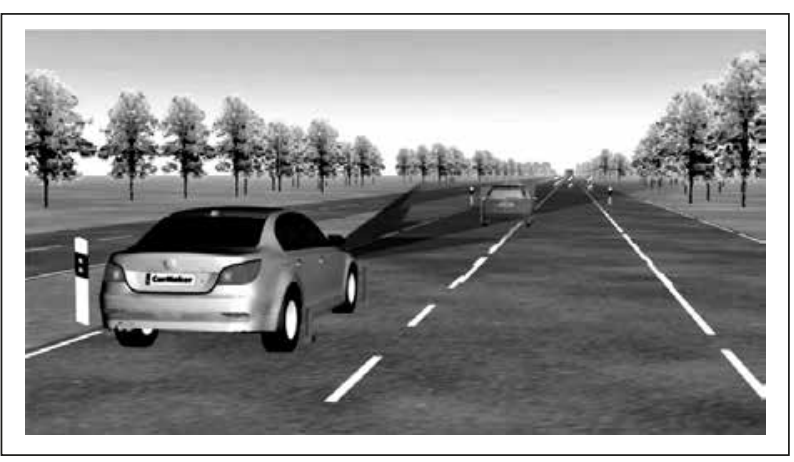

Figure 7 - A view of the IPG CarMake GUI

\subsubsection{Methodology and criterion for minimum acceptable time}

For this study, the vehicle is moving on a triple lane highway at constant speed. At a certain moment of time, an input shown in Figure 8 (top) is applied to the vehicle. The maximum value of steering angle, shown by $\theta$ in this figure, is determined based on the lateral position of the vehicle at the end of the manoeuvre. In other words, $\theta$ is determined such that the lateral displacement of the vehicle at the end of the manoeuvre equals road width, i.e. $3.75 \mathrm{~m}$. After calculating $\theta$, manoeuvre time $t_{m}$, is reduced by 0.05 -second steps until vehicle hits instability boundary. The obtained time is the minimum attainable time for the lane change, recorded as $\left(t_{m}\right)_{\min }$, considering environment and vehicle conditions. This scenario is repeated for velocities between 60 to $120 \mathrm{~km} / \mathrm{h}$ with the increment $20 \mathrm{~km} / \mathrm{h}$. For each specific velocity, maximum tyre-road friction coefficient from 0.1 to 1.2 with increment 0.1 are considered. All the experiments are executed for the loaded and unloaded vehicle, conveying passengers. In total, 96 simulations are conducted.

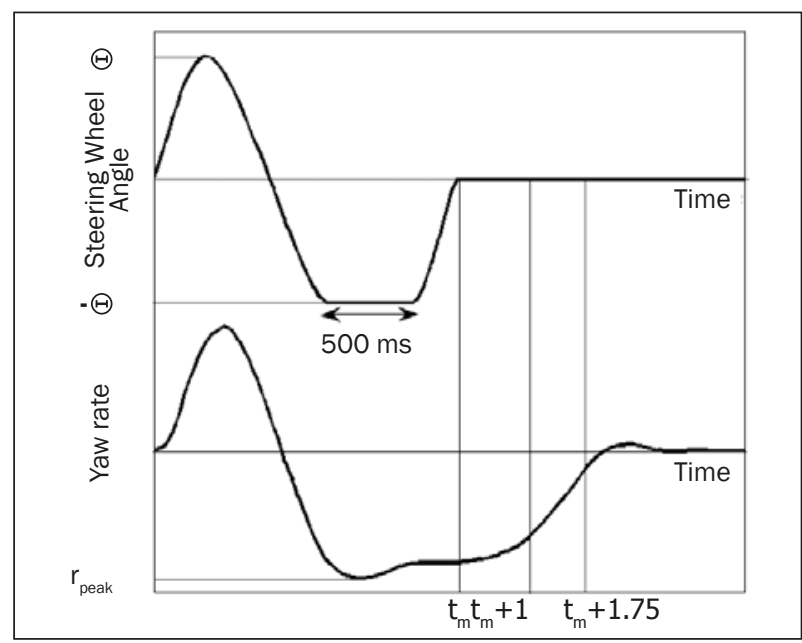

Figure 8 - Steering input and estimation of stability based on the corresponding yaw rate [41]

Vehicle stability is analyzed based on ESC system standard [41]. Based on this standard, the performance of the ESC system is acceptable if, in case of a change in the steering wheel (Figure 8, top), the yaw rate does not exceed $35 \%$ and $25 \%$ of $r_{\text {peak }}$ (Figure 8 , bottom) after 1 and $1.7 \mathrm{~s}$ from the end of the manoeuvre, respectively. In Figure $8, r_{\text {peak }}$ indicates the maximum change in the yaw rate during the manoeuvre. Important vehicle parameters are presented in Table 2.

As an example, the time history of lateral acceleration and yaw rate in two different cases are shown in Figure 9. In this scenario, the vehicle is moving at the constant velocity of $80 \mathrm{~km} / \mathrm{h}$. The sine dwell input on the steering wheel with a frequency of $0.33 \mathrm{~Hz}$ and value of 90 degrees is applied to the steering system after $1 \mathrm{~s}$. The tyre-road friction potential in the first

Table 2 - Important parameters of the vehicle

\begin{tabular}{|c|c|c|c|}
\hline Vehicle's CG distance from front axle & 1.268 & Coefficient of rear spring & $30,000 \mathrm{~N} / \mathrm{m}$ \\
\hline Vehicle's CG distance from rear axle & $1.62 \mathrm{~m}$ & Coefficient of front damper (Push) & $2,500 \mathrm{Ns} / \mathrm{m}$ \\
\hline Distance between front wheels & $1.558 \mathrm{~m}$ & Coefficient of front damper (Pull) & $5,000 \mathrm{Ns} / \mathrm{m}$ \\
\hline Distance between rear wheels & $1.582 \mathrm{~m}$ & Coefficient of rear damper (Push) & $3,000 \mathrm{Ns} / \mathrm{m}$ \\
\hline Mass of vehicle & $2,064 \mathrm{~kg}$ & Coefficient of rear damper (Pull) & $6,000 \mathrm{Ns} / \mathrm{m}$ \\
\hline Coefficient of front spring & $25,000 \mathrm{~N} / \mathrm{m}$ & Rack travel to Steering pinion angle & $100 \mathrm{rad} / \mathrm{m}$ \\
\hline
\end{tabular}


scenario (solid line) is 0.9 and in the second scenario (dashed line) is 0.2. Based on the result of Figure 9 and according to the evaluation criterion of [41], the vehicle is unstable in the second manoeuvre. Hence, the lane change time is not acceptable and needs to be increased.

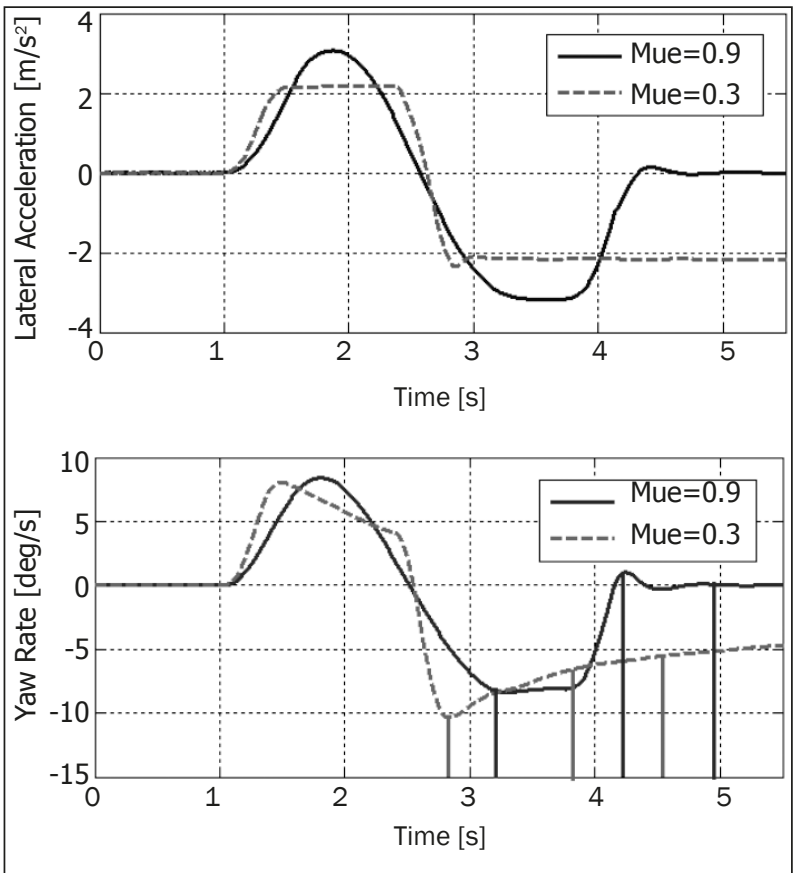

Figure 9 - Lateral acceleration and yaw rate of the ego vehicle in response to sin dwell input to the steering wheel

\subsubsection{Simulation results}

The analysis of the simulation results, illustrated in Figure 10, leads to the following,
1) Decrease in friction and vehicle mass and increase in speed, produces a smaller minimum acceptable time for the manoeuvre.

2) Vehicle mass increase does not affect manoeuvre time monotonically. In other words, mass increase may lead to a larger manoeuvre time in some conditions, but in other condition manoeuvre time may be reduced.

3) Velocity change has more influence on manoeuvre time increase in the presence of small friction rather than large friction.

4) The minimum acceptable time is highly dependent on maximum tyre-road friction coefficient potential.

For a better analysis of the produced curves, the influence of the mass on manoeuvre the minimum time $\left(t_{m}\right)_{\min }$ is applied in a different manner. For this purpose, two available curves shown in Figure (8), are integrated together. In the integration procedure, for each specific velocity and mass, the larger time value is selected. For instance, at $120 \mathrm{~km} / \mathrm{h}$ (solid line) with the friction of 0.1 , the values of time in both curves are compared. This time is $6 \mathrm{~s}$ for the unloaded vehicle, and $5.15 \mathrm{~s}$ for the loaded vehicle with passengers. By choosing the larger time, it is guaranteed that the computed manoeuvre time is acceptable for any condition in between.

Figure 11 shows the 3-D diagram of the manoeuvre time in terms of mass, velocity and tyre-road friction. The illustrated surface divides the space into two parts. The volume above the surface indicates acceptable manoeuvre time.

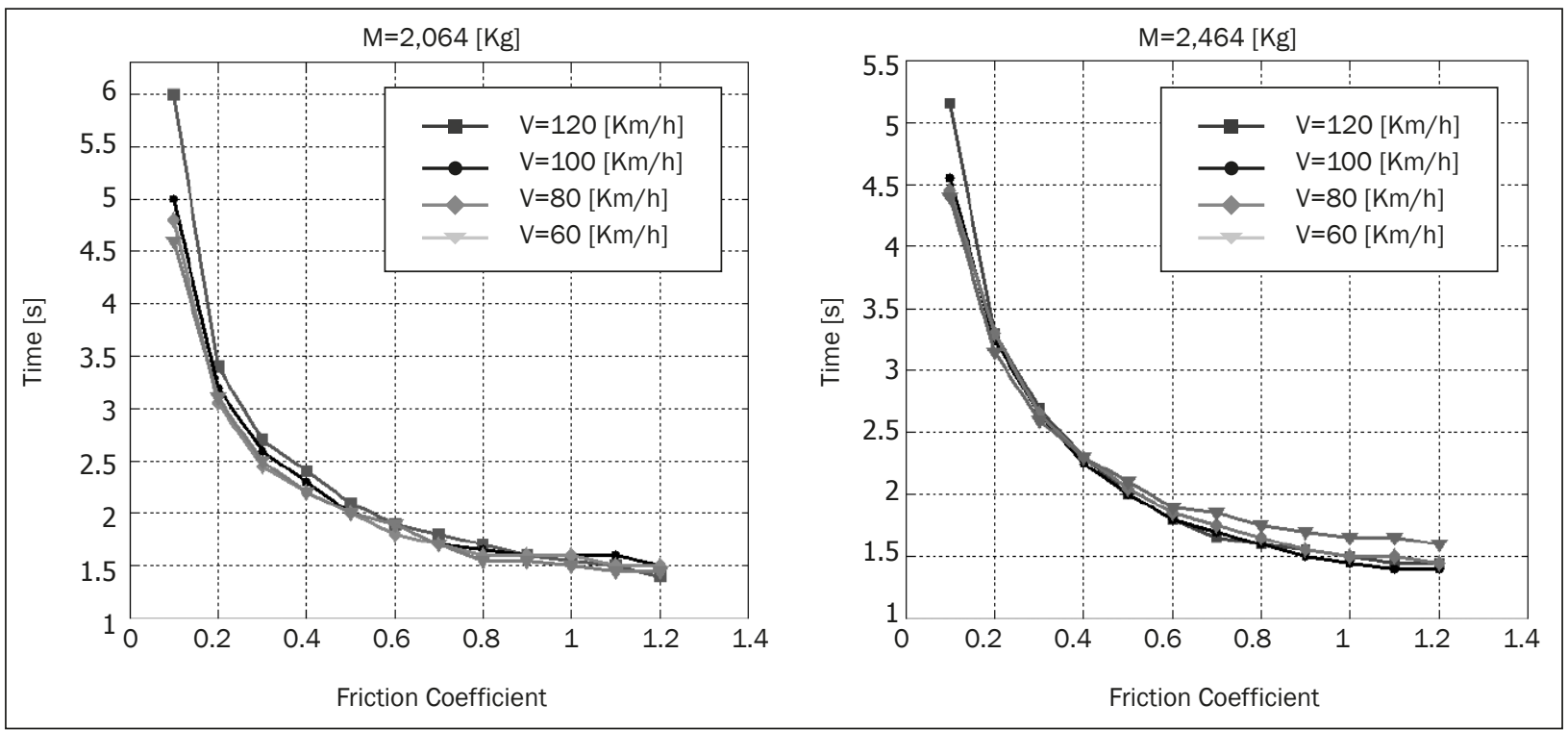

Figure 10 - Time duration of lane change manoeuvre based on different velocities, vehicle masses, and road conditions 


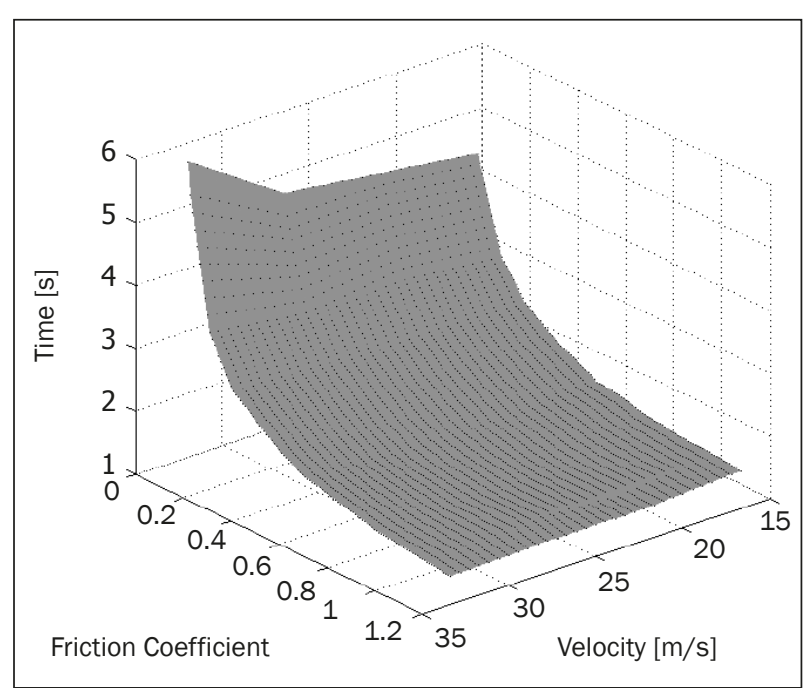

Figure 11 - 3-D diagram of the manoeuvre time in terms of different weight, velocity and maximum tyre-road friction coefficient

The time values below the surface are not acceptable as they do not satisfy the stability criterion as explained earlier. The points on the surface correspond to the minimum acceptable time. The results of different simulations are approximated by (30), where the minimum manoeuvre time $t_{m}$ is expressed in terms of maximum tyre-road friction coefficient $\mu$ and vehicle velocity $v_{x}$

$$
t_{m}\left(\mu, v_{x}\right)=\frac{\mu\left(8+0.5 v_{x}\right)+5}{10 \mu}
$$

The presented model in (30) is labelled TUG-LCA. This model can be illustrated in 3-D as shown in Figure 12. The TUG-LCA model has the following characteristics:

1) It is entirely above the generated surface;

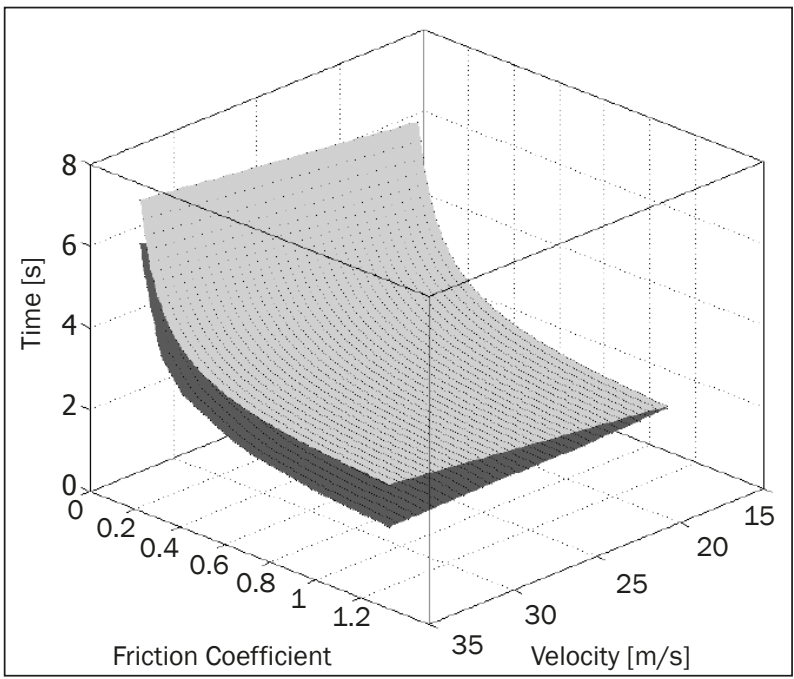

Figure 12 - TUG-LCA lane change time duration model
2) The distance between this model and the main surface is due to a safety factor considered for the manoeuvre. The safety factor attains the highest value for high velocities and low frictions. The difference between the main surface and the TUGLCA is shown in Figure 13;

3) The computational burden is low and hence suitable for real-time calculations;

4) The TUG-LCA model has to be computed for any specific vehicle.

Although the results are only presented for a specific passenger cars with the parameters that are described in Table 2, the same procedure can be applied to all non-articulated vehicles such as any type of passenger cars, buses, and heavy vehicles.

\subsection{Decision-Making Strategy}

In this paper, the value of the required parameters to obtain $t_{1}, t_{2}$ and $t_{3}$ based on the aforementioned equations are presented in Table 3.

By calculation and comparison of these times and settings $\left(t_{m}\right)_{\min }=\mathrm{t}_{4}$, the decision can be made. Table 4 presents the possible lane change cases along with the acceptable time or time interval for the manoeuvre.

Table 3 - Value of the parameters

\begin{tabular}{|c|c|c|c||}
\hline \hline Par. & Value & Par. & Value \\
\hline \hline$C_{1}$ & $1(\mathrm{~m})$ & $\mathrm{w}_{\mathrm{A}}$ & $1.65(\mathrm{~m})$ \\
\hline$W_{E}$ & $1.56(\mathrm{~m})$ & $\mathrm{s}_{0}$ & $2(\mathrm{~m})$ \\
\hline$t_{d}$ & $0.5(\mathrm{~s})$ & $a_{E b}$ & $0.7 \mathrm{~g}\left(\mathrm{~m} / \mathrm{s}^{2}\right)$ \\
\hline
\end{tabular}

As an example, the second case in Table 4 is considered. In this case, $t_{1}>t_{2}>t_{3}>t_{4}$, as shown in Figure 14 .

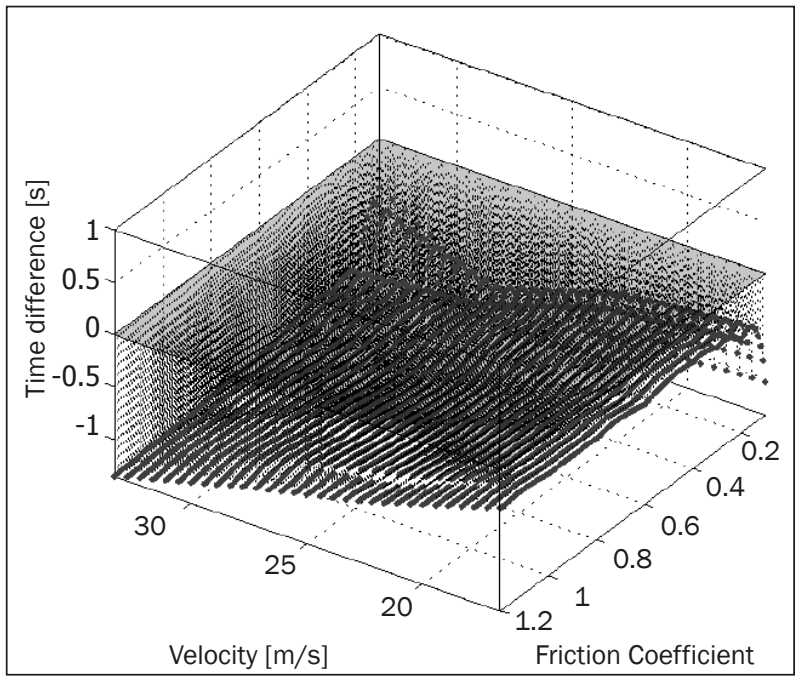

Figure 13 - The difference between the main surface and the TUG-LCA model 


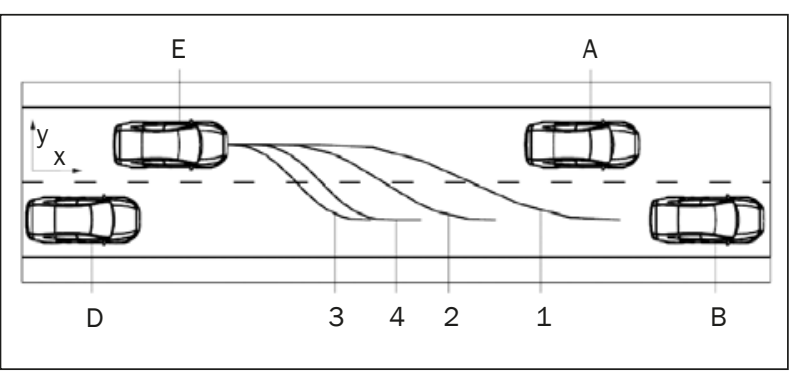

Figure 14 - An example of possible paths based on different constraints

As presented, a trajectory between paths 1 and 2 cannot be selected, because the constraint of trajectory 2 , i.e. $C_{2}$, is not fulfilled. Moreover, all trajectories between paths 3 and 4 , violate constraint $C_{4}$. Hence, safe trajectory for lane change manoeuvre in this example can be any path which is located between trajectories 2 and 4.

The selection of the final suitable path can be made based on different criteria such as fuel and manoeuvre time minimization or passenger comfort maximization, which is not the focus of this paper. Obviously, if the comparison of the computed time does not correspond to any of the cases presented in Table 4, the lane change manoeuvre is not allowed. If any of the three vehicles $A, B$ and $D$ does not exist on the path, its corresponding time is eliminated from calculations. For instance, if vehicle A does not exist, time $t_{1}$ will be eliminated and in case vehicle $D$ does not exist, time $t_{3}$ is removed. In case of absence of all three vehicles, the time value $t_{m}=4.3 \mathrm{~s}$ in section $4-4$ will be used for the manoeuvre. In this case, it must be checked that this time value is larger than the minimum acceptable time produced by the TUG-LCA model; i.e. $t_{m}>t_{4}$.

\section{CONCLUSION}

This paper has proposed an automatic lane change decision-making algorithm for vehicles on a straight highway. The proposed algorithm considers vehicle dynamics and environmental conditions for decision making on lane change. In addition of taking into consideration the lateral position of other vehicles and maximum tyre-road friction coefficient potential, the proposed algorithm outputs a suitable time interval for lane change. For this purpose, firstly the equations for lateral displacement of the vehicle in terms of manoeuvre time were developed. Then, the critical manoeuvre time was calculated based on the introduced constraints. Finally, the decision on lane change was made by comparing the obtained time values and the suitable manoeuvre time duration was generated using a logical procedure. Various simulations were carried out considering tyre-road friction and vehicle velocity and mass. Then a model called TUG-LCA model was developed which transferred the results of off-line simulations into a real-time capable look-up table.

The advantages and innovations of the proposed algorithm include (1) inclusion of the effect of the lateral displacement of the vehicles and tyre-road friction, (2) respecting vehicle dynamics, and (3) providing real-time performance. Hence, in case of any environmental change in the middle of the manoeuvre, the modification of the path is possible. In other words, the dynamics of the process has been integrated into the proposed algorithm. Flexibility in decision-making process is (4) another advantage of the algorithm. In other words, in case of change in algorithm parameters and hence setting more conservative requirements, the safety of the manoeuvre can be enhanced. However, there might be a considerable difference between the generated and optimal path due to the imposed restrictions. On the other hand, by relaxation of the boundary conditions and hence lowering safety factors, the possibility of achieving the optimal path is increased. The simulations implemented in IPG CarMaker confirmed the effectiveness of the proposed algorithm.

During development of the proposed algorithm, some restrictions were imposed, as stated below, which are the topics for future studies,

- The vehicle moves along a highway and on a straight lane, road curvature and slope have been excluded.

- The lane changing vehicle has zero longitudinal acceleration and lane change takes place at a con-

Table 4 - Vehicle dynamic specifications of the vehicle used in simulations

\begin{tabular}{|c|c|c|c|c|c|}
\hline No. & Case & $\begin{array}{c}\text { Acceptable time } \\
\text { (range) }\end{array}$ & No. & Case & $\begin{array}{c}\text { Acceptable time } \\
\text { (range) }\end{array}$ \\
\hline 1 & $t_{1}>t_{2}>t_{4}>t_{3}$ & {$\left[\begin{array}{ll}t_{2} & t_{4}\end{array}\right]$} & 8 & $\mathrm{t}_{2}>\mathrm{t}_{1}=\mathrm{t}_{3}>\mathrm{t}_{4}$ & $t_{1}$ \\
\hline 2 & $t_{1}>t_{2}>t_{3}>t_{4}$ & {$\left[\begin{array}{ll}t_{2} & t_{3}\end{array}\right]$} & 9 & $\mathrm{t}_{1}>\mathrm{t}_{2}=\mathrm{t}_{4}>\mathrm{t}_{3}$ & $t_{2}$ \\
\hline 3 & $\mathrm{t}_{2}>\mathrm{t}_{1}>\mathrm{t}_{4}>\mathrm{t}_{3}$ & {$\left[\begin{array}{ll}t_{1} & t_{4}\end{array}\right]$} & 10 & $\mathrm{t}_{1}>\mathrm{t}_{2}=\mathrm{t}_{3}>\mathrm{t}_{4}$ & $\mathrm{t}_{2}$ \\
\hline 4 & $\mathrm{t}_{2}>\mathrm{t}_{1}>\mathrm{t}_{3}>\mathrm{t}_{4}$ & {$\left[\begin{array}{ll}t_{1} & t_{3}\end{array}\right]$} & 11 & $\mathrm{t}_{2}>\mathrm{t}_{1}>\mathrm{t}_{4}=\mathrm{t}_{3}$ & {$\left[\begin{array}{ll}t_{1} & t_{3}\end{array}\right]$} \\
\hline 5 & $\mathrm{t}_{1}=\mathrm{t}_{2}>\mathrm{t}_{4}>\mathrm{t}_{3}$ & {$\left[\begin{array}{ll}t_{1} & t_{4}\end{array}\right]$} & 12 & $t_{1}>t_{2}>t_{4}=t_{3}$ & {$\left[\begin{array}{ll}t_{2} & t_{3}\end{array}\right]$} \\
\hline 6 & $t_{1}=t_{2}>t_{3}>t_{4}$ & {$\left[\begin{array}{ll}t_{1} & t_{3}\end{array}\right]$} & 13 & $\mathrm{t}_{1}=\mathrm{t}_{2}=\mathrm{t}_{3}>\mathrm{t}_{4}$ & {$\left[\begin{array}{ll}t_{1} & t_{3}\end{array}\right]$} \\
\hline 7 & $\mathrm{t}_{2}>\mathrm{t}_{1}=\mathrm{t}_{4}>\mathrm{t}_{3}$ & $t_{1}$ & 14 & $\mathrm{t}_{1}=\mathrm{t}_{2}=\mathrm{t}_{4}=\mathrm{t}_{3}$ & $t_{1}$ \\
\hline
\end{tabular}


stant longitudinal velocity. In real world conditions, velocity change during the manoeuvre is possible.

- If lane change is not possible, the developed system produces no suggestion for speed increase or decrease to facilitate lane change manoeuvre. Only the current lateral position and velocity of the vehicle is maintained until suitable lane change condition occurs.

A systematic approach for evaluating the algorithm performance in infinite possible number of traffic situations is an essential outlook for the study.

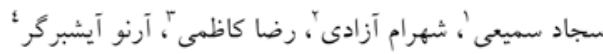

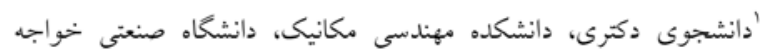

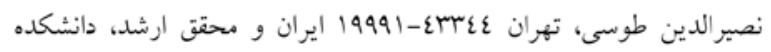

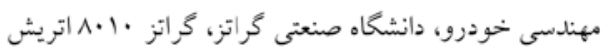

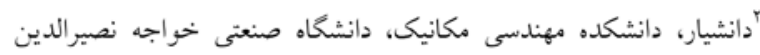

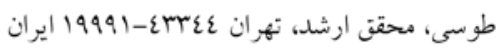

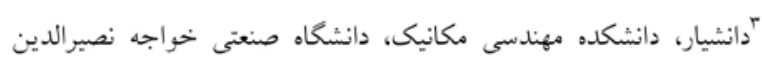

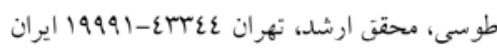

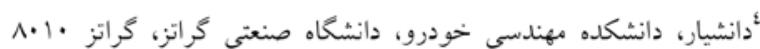

$$
\begin{aligned}
& \text { اتريش }
\end{aligned}
$$

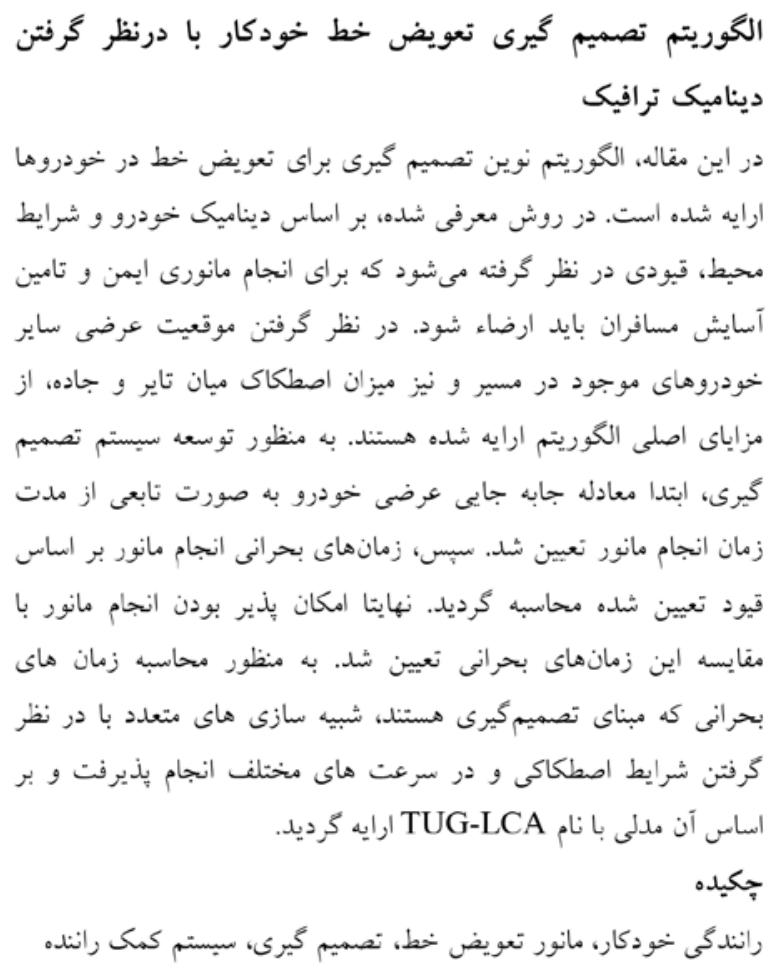

\section{REFERENCES}

[1] Mathew TV. Lane Changing Models. In: Transportation Systems Engineering. 2014; p. 15.1-15.12.

[2] [2] Djenouri D, Soualhi W, Nekka E. VANET's Mobility Models and Overtaking: An Overview. 3rd International
Conference on Information and Communication Technologies: From Theory to Applications (ICTTA). 2008; p. 1-6.

[3] Wang J, Chai R, Wu G. Changing Lane Probability Estimating Model Based on Neural Network. 26th Chinese Control and Decision Conference (CCDC). 2014; p. 3915-3920.

[4] Gipps PG. A Model for the Structure of Lane-changing Decisions. Transportation Research Part B: Methodological. 1986;20(5):403-414. doi: 10.1016/01912615(86)90012-3

[5] Hetrick S. Examination of Driver Lane Change Behavior and the Potential Effectiveness of Warning Onset Rules for Lane Change or "Side" Crash Avoidance Systems [Master Thesis]. Virginia Polytechnic Institute \& State University; 1997.

[6] Penghui L, Mengxia H, Wenhui Z, Xiaoqing X, Yibing L. Steering Behavior during Overtaking on Freeways. Proceedings of the 5th International Conference on Computing for Geospatial Research and Application; 2014 Aug 4-6; Washington DC; 2014. p. 117-118.

[7] Lee HK, Barlovic R, Schreckenberg M, Kim D. Mechanical Restriction Versus Human Overreaction Triggering Congested Traffic States. Physical Review Letters. 2004;92(23):1-4. doi: 10.1103/PhysRevLett.92.238702.

[8] Habel L, Schreckenberg M. Asymmetric Lane Change Rules for a Microscopic Highway Traffic Model. Proceedings of the 11th International Conference on CelIular Automata for Research and Industry (ACRI); 2014 Sep 22-25; Krakow, Poland; Springer International Publishing; 2014. p. 620-629.

[9] Ghaffari A, Khodayari A, Arvin S, Alimardani F. Lane Change Trajectory Model Considering the Driver Effects Based on MANFIS. International Journal of Automotive Engineering. 2012;2(4):261-275.

[10] Song X, Cao H, Huang J. Vehicle Path Planning in Various Driving Situations Based on the Elastic Band Theory for Highway Collision Avoidance. Proceedings of the Institution of Mechanical Engineers, Part D: Journal of Automobile Engineering. 2013; p. 1706-1722.

[11] Yoon J. Path Planning and Sensor Knowledge Store for Unmanned Ground Vehicles in Urban Area Evaluated by Multiple Ladars [PhD thesis]. University of Florida; 2011.

[12] El-Hajjaji A, Ouladsine M. Modeling Human Vehicle Driving by Fuzzy Logic for Standardized ISO Double Lane Change Maneuver. 10th IEEE International Workshop on Robot and Human Interactive Communication. 2001; p. 499-503.

[13] Nilsson J, Sjoberg J. Strategic Decision Making for Automated Driving on Two-lane, One Way Roads Using Model Predictive Control. IEEE Intelligent Vehicles Symposium (IV). 2013; p. 1253-1258.

[14] Zhang S, Deng W, Zhao Q, Sun H, Litkouhi B. Dynamic Trajectory Planning for Vehicle Autonomous Driving. IEEE International Conference on Systems, Man, and Cybernetics (SMC). 2013; p. 4161-4166.

[15] Toledo T, Zohar D. Modeling Duration of Lane Changes. Transportation Research Record: Journal of the Transportation Research Board. 2007; p. 71-78. doi: http://dx.doi.org/10.3141/1999-08. 
[16] Xiaorui W, Hongxu Y. A Lane Change Model with the Consideration of Car Following Behavior. Procedia - Social and Behavioral Sciences. 2013;96:2354-2361. doi:10.1016/j.sbspro.2013.08.264.

[17] Shamir T. How Should an Autonomous Vehicle Overtake a Slower Moving Vehicle: Design and Analysis of an Optimal Trajectory. IEEE Transactions on Automatic Control. 2004;49(4):607-610. doi: 10.1109/ TAC.2004.825632.

[18] Hult R, Sadeghi Tabar R. Path Planning for Highly Automated Vehicles [Master Thesis]. Chalmers University of Technology, Gothenburg, Sweden; 2013.

[19] Ahmed KI. Modeling Drivers' Acceleration and Lane Changing Behavior [PhD thesis]. Massachusetts Institute of Technology; 1999.

[20] Keller CG, Dang T, Fritz H, Joos A, Rabe C, Gavrila DM. Active Pedestrian Safety by Automatic Braking and Evasive Steering. IEEE Transactions on Intelligent Transportation Systems. 2011;12(4):1292-1304. doi: 10.1109/TITS.2011.2158424.

[21] Jula H, Kosmatopoulos EB, Ioannou PA. Collision Avoidance Analysis for lane Changing and Merging. IEEE Transactions on Vehicular Technology. 2000;49(6):2295-2308. doi: 10.1109/25.901899.

[22] Chen YL, Wang CA. Vehicle Safety Distance Warning System: A Novel Algorithm for Vehicle Safety Distance Calculating Between Moving Cars. IEEE 65th Vehicular Technology Conference (VTC). 2007; p. 2570-2574.

[23] Feng G, Wang W, Feng J, Tan H, Li F. Modelling and Simulation for Safe Following Distance Based on Vehicle Braking Process. IEEE 7th International Conference on e-Business Engineering (ICEBE). 2010; p. 385-388.

[24] Wu Y, Xie J, Du L, Hou Z. Analysis on Traffic Safety Distance of Considering the Deceleration of the Current Vehicle. Second International Conference on Intelligent Computation Technology and Automation (ICICTA). 2009; p. 491-494.

[25] Chen YL, Wang SC, Wang CA. Study on Vehicle Safety Distance Warning System. IEEE International Conference on Industrial Technology (ICIT). 2008; p. 1-6.

[26] Salvucci DD, Liu A. The Time Course of a Lane Change: Driver Control and Eye-movement Behavior. Transportation Research Part F: Traffic Psychology and Behavior. 2002;5(2):123-132.

[27] Lee G. Modeling Gap Acceptance at Freeway Merges [Master Thesis]. Massachusetts Institute of Technology; 2006.

[28] Thiemann C, Treiber M, Kesting A. Estimating Acceleration and Lane-changing Dynamics Based on NGSIM
Trajectory Data. 87th Transportation Research Board Annual Meeting; 2008.

[29] Gurupackiam S, Lee JS. Empirical Study of Accepted Gap and Lane Change Duration within Arterial Traffic under Recurrent and Non-recurrent Congestion. International Journal for Traffic and Transport Engineering. 2012;2(4):306-322. doi: 10.7708/ijtte.

[30] Cao X, Young W, Sarvi M. Exploring Duration of Lane Change Execution. Australasian Transport Research Forum; 2013.

[31] Caywood WC, Donnelly HL, Rubinstein N. Guideline for Ride-quality Specifications Based on Transpo ' 72 Test Data. Johns Hopkins University Applied Physics Laboratory, Washington. 1977. Tech. Rep: 00168889.

[32] Samiee S, Azadi S, Kazemi S, Hatamian Haghighi AH, Ashouri MR. The Effect of Torque Feedback Exerted to Driver's Hands on Vehicle Handling - A Hardware-in-the-loop Approach. Systems Science \& Control Engineering. 2015;3(1):129-141. doi: 10.1080/21642583.2014.996918.

[33] Jazar RN. Vehicle Dynamics: Theory and Applications. New York, USA: Springer; 2008.

[34] Lex C, Eichberger A, Hirschberg W. Methods to Estimate the Tire Road Friction for Advanced Driver Assistance Systems. ATZ Worldwide. 2011;113(12):56-61.

[35] Albers A, Düser T. Implementation of a Vehicle-in-theLoop Development and Validation Platform. FISITA World Automotive Congress; 2010.

[36] Anonymous "CarMaker User's Guide”. IPG Automotive GmbH, Vol. 4; 2012.

[37] Ziegler S, Höpler R. Extending the IPG CarMaker by FMI Compliant Units. 8th International Modelica Conference. 2011; p. 779-784.

[38] Huber F, Hickel G, Hammann K, Leonhard V, Schmidt E, Schik W, Tschritter P, Weilacher V, Wurster U. IPG CarMaker Pro, vol. 4.0.3; 2012.

[39] Martinus M, Deicke M, Folie M. Virtual Test Driving Hardware-Independent Integration of Series Software. ATZ Elektronik. 2013;8(5):16-21.

[40] Schwab S, Leichsenring T, Zofka MR, Baer T. Consistent Test Method for Assistance Systems. ATZ Worldwide. 2014;116(9):38-43. doi: 10.1007/s38311-0140216-x.

[41] Anonymous. The New Car Assessment Program Electronic Stability Control System Testing. U.S. Department of Transportation, National Highway Traffic Safety Administration; 2013. 